\title{
The Transformation of Scientific Knowledge Concerning Evolution into the Content of the Curriculum and its Potential to Create a Conceptual Change in the Conceptual Structures of Pupils
}

\author{
Jana Fančovičová ${ }^{\text {* }}$ \\ ${ }^{1}$ Department of Biology, Faculty of Education, Trnava University, Priemyselná, Trnava, SLOVAKIA
}

Received 15 February 2019 - Revised 27 March 2019 - Accepted 6 April 2019

\begin{abstract}
Understanding of evolution helps solve biological problems in areas that affect our lives. One of the ways of adopting the concept of evolution leads through a conceptual change. We investigated whether inductively prepared educational activities, focused on evolution, have the potential to create conceptual changes in students' conceptual structures. We used a quasi-experimental design with pre- and post-tests in four classes with $10-16$ year-old students. To measure their knowledge and understanding of evolution, we used two different instruments. Students who have received an education about evolution obtained significantly more factual knowledge. Pupils who participated in active education focused on diversity and adaptation of organisms, achieved not only a higher level of knowledge, but the transfer came also to an understanding of evolutionary mechanisms. Using appropriately chosen examples illustrating evolution will enable pupils to confront their naive ideas and misconceptions with scientific reality and can influence students' understanding of evolution.
\end{abstract}

Keywords: conceptual change, evolution, education, pupils, understanding

\section{INTRODUCTION}

Evolution is the cornerstone of not only biology but also science as a whole. Scientific literacy concerning evolution is a key in issues of climate change, food safety, increasing resistance to antibiotics, the spread of new infectious diseases (Gluckman et al., 2011) and the degradation of biodiversity. It is also important in the light of the current worldwide spread of hate groups since social cohesion is partly due to the recognition that human diversity is also the result of evolutionary processes.Evolutionary theory involves different areas of biology and is essential to understanding many biological themes.

Although evolutionary theory is a recognized scientific theory, even more than 150 years after Darwin's ideas of evolution, it is constantly facing criticism and rejection by individuals. Despite extensive scientific findings demonstrating molecular and phenotypic changes over time, research continues to confirm the absence of a scientific understanding of biological evolution by the public (Scott, 2005), which results from a lack of understanding of the underlying principles of evolution. More than one third of Americans disagree with the theory of evolution (Kampourakis \& Strasser, 2015).

In addition to the lay public, both pupils and teachers have an insufficient knowledge of evolution. A difference in knowledge and evolutionary attitudes was not confirmed among secondary school students studying and notstudying biology (Šorgo et al., 2014), and there was no confirmation of a difference in an understanding of the importance of evolutionary education among biology teachers and English language teachers (Osif, 1997). The same results were found by Nehm, Kim, and Sheppard (2009), who compared the attitudes of secondary school biology teachers and humanities teachers to evolution. Teachers not only face many evolutionary issues they cannot answer, but active rejection of Darwinian Theory continues amongst students and teachers themselves (Irez \& Bakanay, 2011). Other causes include a lack of opportunities to express an opinion on various issues regarding

(C) 2019 by the authors; licensee Modestum Ltd., UK. This article is an open access article distributed under the terms and conditions of the Creative Commons Attribution License (http://creativecommons.org/licenses/by/4.0/). \fankaj@gmail.com (*Correspondence) 


\section{Contribution of this paper to the literature}

- Inductively prepared educational activities have the potential to create conceptual changes in students' conceptual structures.

- Students who have completed evolutionary education have achieved a higher level of understanding of evolutionary processes.

- Evolutionary theory can be integrated into the education system in an appropriate way.

evolution (Clores \& Limjap, 2006). The rejection of evolution is also influenced by religion (Miller \& Toth, 2014), but religiosity does not necessarily mean non-acceptance of evolution (Reiss, 2011). In an absence or misunderstanding of evolution, it is assumed that other topics will not be correctly interpreted (Losch \& Nzekwe, 2011).

The alarming fact is that despite the recommendations of many research findings, evolutionary theory is not sufficiently integrated into the education system. A number of fundamentalist groups are actually trying to remove evolution from the curriculum. A consequence of this is not only the integrity of science but also the natural literacy of students (Bybee, 2002). The topic of evolution absent in school documents, and only a small percentage of teaching time (Rutledge \& Mitchell, 2002) is dedicated to the evolutionary issue during the school year. Slovak textbooks lack definitions of evolution and education standards do not contain evolutionary themes. By analyzing Slovak biology textbooks for primary schools, we confirmed that school papers do not contain current trends in the biological sciences. Textbooks lack examples which correctly illustrate the interrelationships between the individual taxa during evolution and mainly use linear and spiral diagrams.

The problem of teaching evolution is not only the lack of interest on the part of teachers, but also persistent misconceptions amongst both students and teachers. Evolutionary misconceptions relate, for example, to a misunderstanding of natural selection. Natural selection is a random process and also the belief that evolution can lead to perfection. Some of these are simple misunderstandings; some have been formed in the school environment or media outlets, while others may stem from the purposeful intervention of education. Many praise the assumption that evolution is going in a certain direction and that living organisms can choose to adapt. Jensen and Finley (1996) mention nine areas of misconceptions concerning evolution: Lamarckism, anthropomorphism, teleology, genetics, the time frame of evolution, the concept of species and the individual, the origin and survival of new characters, variability within the population, change in proportional representation of individuals with different characters.

Passing basic courses focused on evolution during university studies confirmed an increase in knowledge about evolution, but misconceptions continued to evolve (Bishop \& Anderson, 1990; Johnson \& Peeples, 1987; Nehm \& Reilly, 2007). The modules designed with a learning cycle implementation helped improve student comprehension of natural selection, particularly for lower-performing students who were not biology majors, and for those who reported less of an interest in evolution (King-Heiden \& Litster, 2018). Wilson (2005) suggests a course of evolution, an evolution for everyone which would focus on the application of evolution to various fields of science, both natural and the social and human sciences. The proposed course was extremely successful (O'Brian, Wilson, \& Hawley, 2009). The misconceptions about evolution were partially eliminated after taking the course in evolutionary psychology (Short \& Hawley, 2015). Ha, Haur, and Nehme (2012) construct of sense of security. Individuals who feel more confident in their knowledge of evolution have a higher degree of acceptance of evolution. Nehm and Reilly (2007) observed an improvement in knowledge of evolution through active learning, using discussion, problem solving and group teaching. Active education increases student engagement in education and positively influences the acquisition of knowledge. Spronken-Smith et al. (2007) state that learningoriented learning is a type of teaching which is the best way for learners to become involved in acquiring their knowledge. The entire learning process is very active. The research itself is both a teaching strategy and a model for the pedagogical process (Bybee, 2002). The aim of the present study was to test the potential of inductively prepared educational activities aimed at evolving an inducement of a conceptual change in the conceptual structures of pupils.

We assumed that pupils who participate in active education, focused on diversity and adaptation of organisms, will not only achieve a higher level of knowledge, but the transfer will come to an understanding of evolutionary mechanisms. 


\section{MATERIALS AND METHODS}

\section{Participants}

The research was carried out in the school year 2017/2018 in the months of September - December at primary school. The total number of respondents involved in the research was 94 , namely the fifth $(\mathrm{N}=49)$, the seventh $(\mathrm{N}$ $=24)$ and the ninth $(\mathrm{N}=21)$. The 8th grade has been eliminated because geology is the content of biology education and the prepared activities could not be incorporated. The average age of the pupils was 12.76 years $(\mathrm{SE}=0.72)$.

The undergoing school research was among schools that use a transversal approach to education and teaching biology. The school was not involved in any project focused on innovative ways of education, nor does it emphasize or evoke evolutionary issues. The school leadership, as well as the teaching subject of biology, have been inclined to these activities and have agreed on the course of the research.

\section{Procedure}

Participants were randomly divided into the groups of four. Each group worked on the same tasks. We prepared six teaching units with practical activities focused on biodiversity and adaptation of organisms. Activities have been developed to be an integral part of the education standards of lower secondary education biology. In the fifth year, evolutionary activities were integrated into the following topics of the fifth year: "We Understand Nature - Methods and Tools of Exploration", "Working with a Microscope", "Understanding Plants and Animals". In the seventh edition of the topics: "Water and Air", and in the ninth year of the themes: "Nutrition and Breathing of Bacteria and Mushrooms", "Basic Processes of Organisms", activities were developed in a structured inquiry. Teachers can incorporate them into their biological lessons as active learning modules and it is ensured that the activities encompassed an evolution aspect so that no additional evolution content introduction is necessary.

Each activity started with a discussion with the pupils about the problem raised, or a text was read which provided a basis for the pupils' ideas. The teacher followed with an active learning activity. The pupils proposed solutions that they subsequently verified. After verifying the proposals, the results were presented, discussed and concluded.

During the first activity, schoolchildren watched what nature was all about. Binoculars and magnifying glasses were available. They recorded their observations in a table and then the terms from the table were categorized into the relevant categories (living, non-living, woody, herb, vertebrate, invertebrate, herbivore, carnivore, and alligator). Another task was focused on the perception of nature through the senses. The pupils recorded everything they saw, heard, felt, caught / caught and tasted / tasted in the school yard. They then prepared examples of dietary relationships, namely between plant and animal and between animals.

The second activity was focused on exploration of the ecosystem. They observed everything in the environment (products of human activity, animals, plants, but also interacting organisms in a given type of ecosystem). The viewed facts were plotted on a worksheet. Subsequently, they investigated environmental factors, namely air and soil temperature, cloud condition, wind direction and precipitation. There were thermometers and labels to measure the direction of the wind. The tasks in the third practical activity were focused on exploration and observation of the woody ecosystem. The aim of this activity was to observe the trees in the school grounds and observe the observed facts in the tables according to the annex to the worksheet.

The fourth practical activity was focused on an exploration of herb ecosystem. Plant drawings and scrapbooks were compared with pictures in the attachment to the field worksheet. At the end of this activity, the Slovak and Latin names of the plants obtained were found using atlases. In another practical activity called "Examination of Soil Properties ", the students worked with different soil samples (field, forest, meadow, school yard).

The aim was to analyze individual soil samples, their appearance, graininess and humidity, in order to detect the presence of living and non-living components in the soil (plants, animals, stones, etc.). If they found plants or animals in the samples, they had to use their atlas to determine their names. The sixth and, at the same time, last practical activity was focused on exploring the life processes of living organisms. They surveyed objects that were laid on a bench and considered whether they met all the properties of the living organisms. They reasoned which objects belonged among the living ones and which among the inanimate natural one. All of these tasks were focused on adaptation of plants and animals.

As a research tool, a questionnaire was used, which was given to the pupil prior to induction as a pretest and then immediately after induction as a post test. The questionnaire sheet concerned not only pupils' knowledge of evolution in general but, in particular, an understanding of the nature of adaptations and natural selection. The questionnaire, taken from Anderson, Fisher, and Norman (2002), which was adapted to the age of reasonableness principle, was used to determine the knowledge and understanding of evolution. The time interval between the two tests was three weeks. The total average time required to complete the questionnaire was 15 minutes, but the 
pupils were not time-bound. The questionnaire contained 21 questions and was divided into two dimensions: 1 . knowledge and 2. understanding of adaptation and natural selection.

The first part of the anonymous questionnaire contained data such as gender, age, and the group name that served to match the respondents' answers - pretest and post-test. The first part of the questionnaire contained 13 closed questions aimed at understanding the evolution of knowledge with a choice of options from disagreement, do not know to the possibility of consent. The three options were deliberately chosen because the questions asked were clear answers that were either true or false. In this case, the pupils marked one of the options, obtaining one point for each correct answer.

The second part of the questionnaire contained open questions. There were situations regarding the adaptation of animals and plants, where the pupil was supposed to explain why the situation occurred. In this part, pupils could obtain five points in all. This was followed by a short accompanying text on Galapagos pinks and six questions about natural selection. The pupil had three choices, with the correct answer only being one of them. For each correct answer, the pupils received one point. The questions explored the understanding of adaptation and evolution. After evaluating the questionnaire, the summary score for both parts, the pupil's overall summary score was calculated and used in further analyses.

\section{Statistical analyses}

We used repeated-measures ANOVA, with sex and grade as predictors, summarizing scores from pre-test and post-test as dependent variables.

\section{RESULTS}

ANOVA revealed that there were differences with respect to grade (Table 1), but the influence of gender was not statistically significant.

Table 1. Results of ANOVA on summarized scores from pre-test and post-test

\begin{tabular}{|c|c|c|c|c|c|}
\hline & SS & DF & MS & $\mathbf{F}$ & $p$ \\
\hline \multicolumn{6}{|l|}{ Between-subject effects } \\
\hline Intercept & 11170.77 & 1 & 11170.77 & 1460,247 & $<0.001$ \\
\hline Sex & 1.30 & 1 & 1.30 & 0.170 & 0.68 \\
\hline Grade & 257.90 & 2 & 128.95 & 16.856 & $<0.001$ \\
\hline Sex $\times$ Grade & 20.18 & 2 & 10.9 & 1.319 & 0.28 \\
\hline Error & 436.05 & 57 & 7.65 & & \\
\hline \multicolumn{6}{|l|}{ Within-subject effects } \\
\hline Pre-Posttest & 1139.35 & 1 & 1139.35 & 213.741 & $<0.001$ \\
\hline Pre-Posttest $\times$ Sex & 8.75 & 1 & 8.75 & 1.642 & 0.21 \\
\hline Pre-Posttest $\times$ Grade & 52.78 & 2 & 26.39 & 4,951 & 0.01 \\
\hline Pre-Posttest $\times$ Sex $\times$ Grade & 6.64 & 2 & 3.32 & 0.623 & 0.54 \\
\hline Error & 303.84 & 57 & 5.33 & & \\
\hline
\end{tabular}

Within-subject analyses showed statistically significant differences between pre-test and post-test (Figure 1) and associations between Pre-Posttest and grade (Table 1). Based on the post-hoc test (Scheffé), we confirmed statistically significant differences between fifth and seventh grade and between seventh and ninth grade (Figure 2). Respondents of education have reached a higher level of knowledge and an evolutionary understanding after the implementation of practical activities focused on the diversity of organisms and their adaptation. 


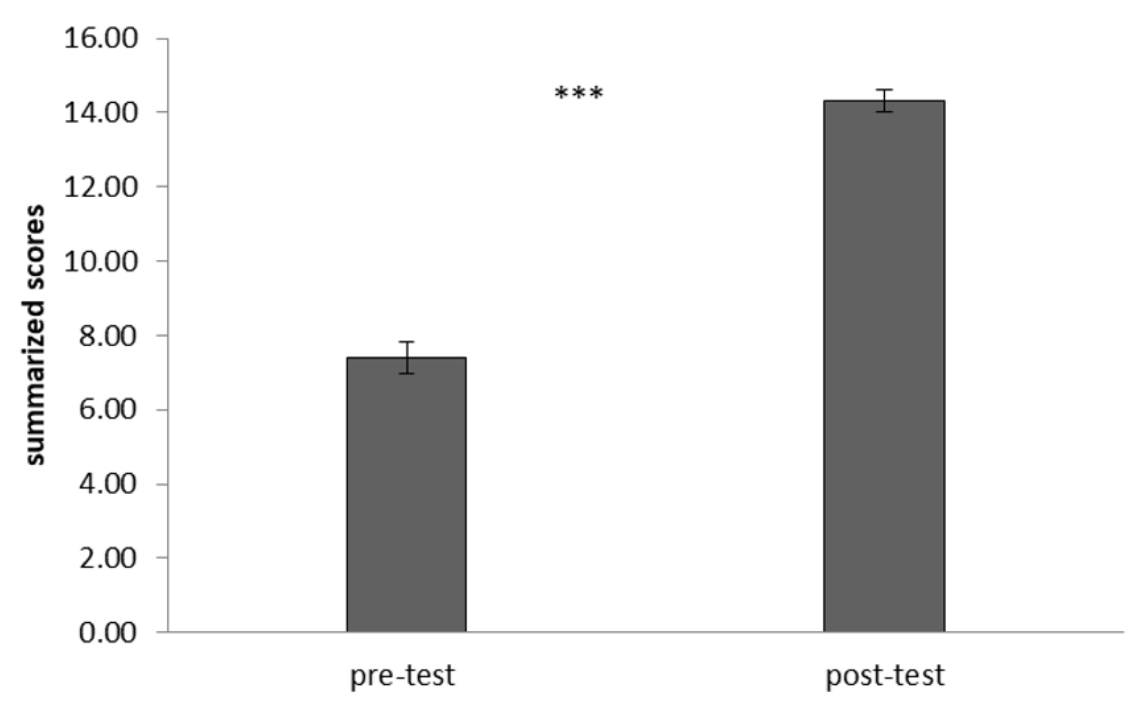

Figure 1. Differences between pre-test and post-test

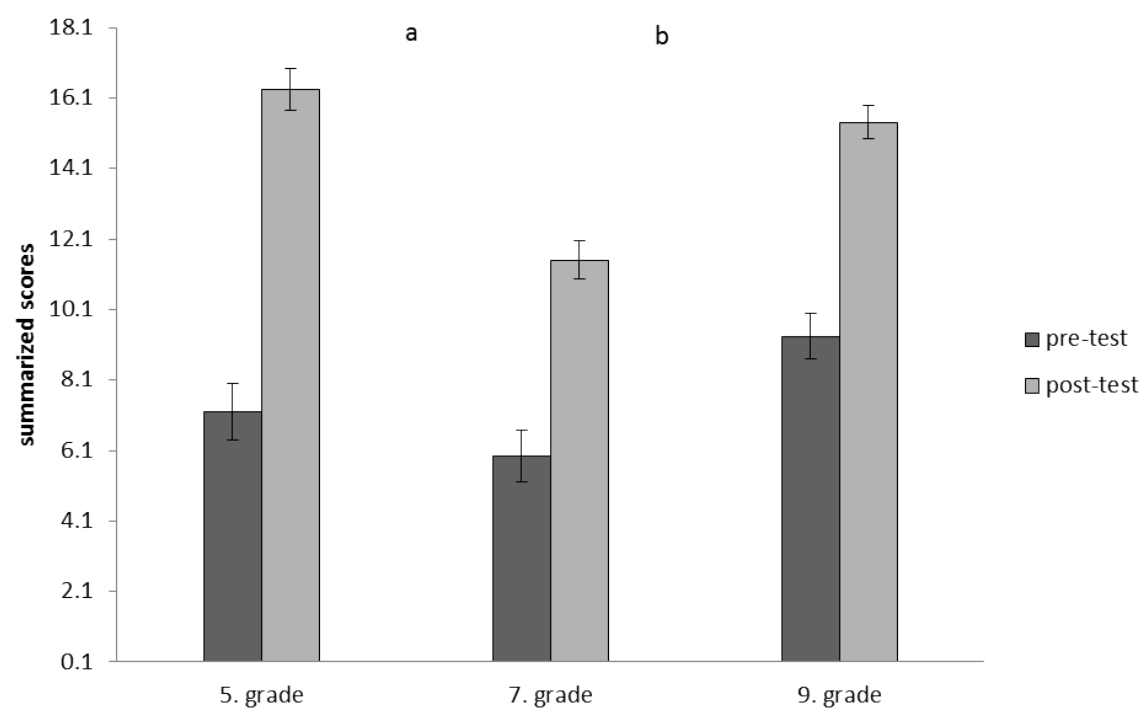

Figure 2. Differences between tests with respect to grade

\section{Knowledge}

Separate ANOVA with predictors listed in Table $\mathbf{1}$ and scores from pre-test and post-test of knowing as dependent variables showed the significant influence of grade (described above) on knowledge scores $\left(\mathrm{F}_{(2,57)}=\right.$ $5.84, p<0.001$ ). Within-subject analysis confirmed statistically significant differences between pre-test and post-test $\left(F_{(1,57)}=163.86, p<0.0001\right)$ and differences between knowledge of grades in post-test $\left(\mathrm{F}_{(2,57)}=7.6, p<0.001\right)$ (knowledge in pre-test were the same in all grades). Post-hoc test (Scheffé) validated differences between the fifth and seventh grades and between the seventh and ninth grades (Figure 3), especially in the fifth grade. Sex was not significant in any of the analysis. 


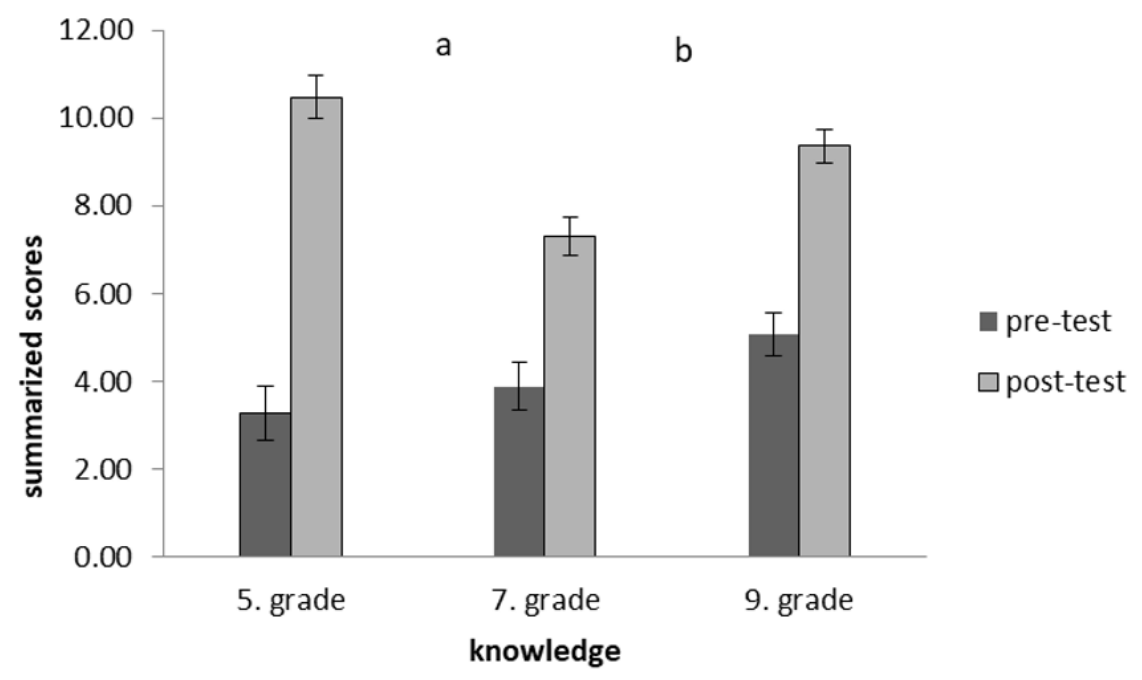

Figure 3. Differences between knowledge with respect to grade

The pupils addressed questions in the knowledge test to indicate whether food is important for humans, animals or plants, or whether evolutionary theory is correct because the Bible is infallible. Pupils had the most common problem with adaptation issues such as bees floating on flowers to pollinate them, or the development of the eye which can only be explained by evolution.

\section{Understanding}

Scores from understanding of evolution were significantly higher in post-tests $\left(\mathrm{F}_{(1,57)}=91.85, p<0.0001\right)$, but there were no significant differences with respect to the student's grade (Figure 4).

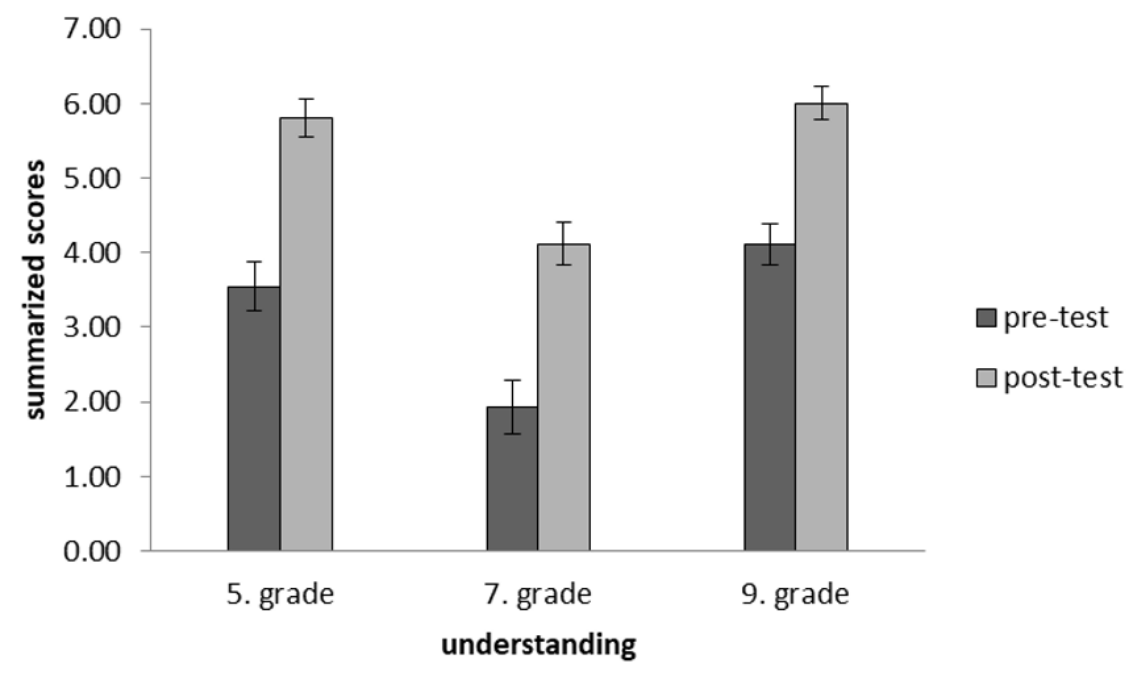

Figure 4. Differences between understandings with respect to grade

Students of lower secondary education achieved a higher score after the realization of practical activities in the dimension of understanding of evolutionary principles. They were able to explain the process of adaptation and natural selection, despite the fact that they were addressing activities aimed at the diversity of organisms during their education.

\section{DISCUSSION}

The aim of the presented research was to analyze pupils' knowledge of evolution and testing of the impact of hands-on activities focused on diversity and adaptation of organisms on the level of understanding of the mechanisms of evolution. The present research has confirmed that inductively prepared educational activities 
aimed at evolution have the potential to create conceptual changes in students' conceptual structures. Students who have completed evolutionary education have achieved a higher level of understanding of evolutionary processes.

Neumann, Boone, and Fischer (2014) investigated the extent to which studying of evolution, with the inclusion of elements of science and nature in teaching (evolutionary activities), improved among students, compared to students who did not have activity in the subject of evolution. The results showed that in the experimental class, where the activities on evolution were included, the students understood and adopted evolution better. In the group of pupils who did not integrate the activities into the teaching process, a better understanding or acceptance of evolution did not occur. It should be noted that we did not examine the acceptance, but only the understanding and knowledge of evolution. These two concepts are, however, not mutually related (e.g., Deniz \& Donnelly, 2011). Our findings are consistent with the results of the Glaze and Goldston study (2015), that if the activities are included in traditional teaching, pupils' knowledge of evolutionary theory can be improved.

To improve the above-mentioned issues, courses of evolution are recommended to increase interest in students, expand their knowledge of evolution, and even stimulate the acceptance of evolution (Wilson, 2005). Cofré et al. (2017) investigated the impact of the course on the acceptance of evolution. Research has confirmed that in a class where evolution was taught by the evolutionary course, pupils improved in terms of the acceptance of evolutionary theory. These results support the claim that active forms of teaching, such as practical activities, can affect not only knowledge but also the acceptance of pupil evolution. One would argue that additional research on acceptance of evolution in the present study would provide more, in-depth understanding of conceptual change. At least in majority of research conducted in the U.S., however, relationships between understanding and acceptance of evolution was missing (for review see Glaze \& Goldston 2015).

Similar research has also confirmed that students who have completed a biological course had a better knowledge of evolution, understood the relationship between genotype and phenotype and were able to explain the nature of the mutations (White, Heidemann, \& Smith, 2013). Nehm and Reilly (2007) also compared the impact of active learning on pupils' knowledge for twelve weeks. They found that in a class where active teaching was preferred, pupils achieved much better results than a class in which only traditional teaching was used. Active learning helped eliminate misconceptions in pupils, and pupils learned more key concepts about natural selection. Although the present study as well as aforementioned research showed that evolution courses increase understanding of evolution, longitudinal research to support whether understanding and personal acceptance of evolution lasts beyond the reporting period of courses is necessary.

\section{CONCLUSION}

Teaching biology without incorporating evolutionary theory is ineffective (Moore, 2002). Another problem is the fact that teachers have a preference for teaching theory and deductive approaches. Teachers should use active teaching and support the analysis of scientific theory in an objective way.

Knowledge of evolution not only affects the quality of school education, but also religious beliefs or the interest of pupils and teachers. Creating the content of educational standards and incorporating evolution into the learning system itself should be in the hands of biology teachers. Evolution should be included in the teaching of biology at primary school, as not all students will have biology or biological seminars at secondary or college lessons to learn about evolution (Moore, 2002). Catley and Novick (2008) emphasize that mainstream charts should be included in the textbooks as they clearly show the current consensus of scientific knowledge.

Literate scientists will be better able to cope with the scientific and technological challenges they face in everyday life and will be able to make decisions that are beneficial to themselves, their families and the whole of society. The research is a preliminary study focused on the possibilities evolutionary activities on the knowledge and understanding without retention test. Further research is required to test the persistence of understanding the mechanisms of evolution. It is necessary to test practical activities focused on natural and sexual selection in the context of understanding od evolution. Teaching evolution requires unified, supportive front across various schools to move public perceptions toward understanding and better acceptance of evolution, one of most fascinating topic of science.

\section{ACKNOWLEDGEMENTS}

We would like to thank all the volunteers who participated in this research. Two referees made insightful comments on earlier drafts of this manuscript. This research was supported by the university grant no. 8/TU/2018 and by grant APVV-14-0070. 


\section{REFERENCES}

Bishop, B. A., \& Anderson, C. W. (1990). Student conceptions of natural selection and its role in evolution. Journal of Research in Science Teaching, 27(5), 415-427. https:/ / doi.org/10.1002/tea.3660270503

Blancke, S., Hjermitslev, H. H., Braeckman, J., \& Kjærgaard, P. C. (2013). Creationism in Europe: Facts, gaps, and prospects. Journal of the American Academy of Religion, 81(4), 996-1028. https:/ / doi.org/10.1093/jaarel/lft034

Bybee, R. W. (2002). We should teach about biological evolution. AIBS Bulletin, 52, 616-618. https:/ / doi.org/10.1641/0006-3568(2002)052[0616:WSTABE]2.0.CO;2

Catley, K. M., \& Novick, L. R. (2008. Seeing the wood for the trees: an analysis of evolutionary diagrams in biology textbooks. BioScience, 58, 976-987. https:/ / doi.org/10.1641/B581011

Clores, M. A., \& Limjap, A. A. (2006. Diversity of students' beliefs about biological evolution. Asia Pacific Journal of Education, 26(1), 65-77. https:/ / doi.org/10.1080/02188790600607960

Cofré, H. L., Santibáñez, D. P., Jiménez, J. P., Spotorno, A., Carmona, F., Navarrete, K., \& Vergara, C. A. (2018). The effect of teaching the nature of science on students' acceptance and understanding of evolution: myth or reality? Journal of Biological Education, 52(3), 248-261. https:/ / doi.org/10.1080/00219266.2017.1326968

Deniz, H., \& Donnelly, L. A. (2011). Preservice secondary science teachers' acceptance of evolutionary theory and factors related to acceptance. Reports of the National Center for Science Education, 31(4).

Glaze, A. L., \& Goldston, M. J. (2015). US science teaching and learning of evolution: A critical review of the literature 2000-2014. Science Education, 99(3), 500-518. https:/ / doi.org/10.1002/ sce.21158

Ha, M., Haury, D. L., \& Nehm, R. H. (2012). Feeling of certainty: uncovering a missing link between knowledge and acceptance of evolution. Journal of Research in Science Teaching, 49(1), 95-121. https:// doi.org/10.1002/tea.20449

Irez, S., \& Bakanay, Ç. D. Ö. (2011). An assessment into pre-service biology teachers' approaches to the theory of evolution and nature of science. Egitim ve Bilim, 36(162), 39.

Jensen, M. S., \& Finley, F. N. (1996). Changes in students' understanding of evolution resulting from different curricular and instructional strategies. Journal of Research in Science Teaching, 33(8), 879-900. https:/ / doi.org/10.1002/(SICI)1098-2736(199610)33:8<879::AID-TEA4>3.0.CO;2-T

Johnson, R. L., \& Peeples, E. E. (1987). The role of scientific understanding in college: student acceptance of evolution. The American Biology Teacher, 49(2), 93-98. https:/ / doi.org/10.2307/4448445

Kampourakis, K., \& Strasser, B. J. (2015). The Evolutionist, the Creationist, and the 'Unsure': Picking-Up the Wrong Fight?. International Journal of Science Education, Part B 5(3), 271-275. https:/ / doi.org/10.1080/21548455.2014.931613

King-Heiden, T. C., \& Litster, M. (2018). Using case-study based modules to promote a better understanding of evolution in an undergraduate anatomy and physiology course. Journal of Biological Education, 1-15. https: / doi.org/10.1080/00219266.2018.1501406

Miller, J. S., \& Toth, R. (2014). The Process of Scientific Inquiry as It Relates to the Creation/Evolution Controversy. The American Biology Teacher, 76(4), 238-241. https:/ / doi.org/10.1525/abt.2014.76.4.4

Moore, R. (2002). Teaching evolution: do state standards matter? AIBS Bulletin, 52, $378-381$. https:/ / doi.org/10.1641/0006-3568(2002)052[0378:TEDSSM]2.0.CO;2

Nehm, R. H., \& Reilly, L. (2007). Biology majors' knowledge and misconceptions of natural selection. BioScience, 57(3), 263-272. https:/ / doi.org/10.1641/B570311

Nehm, R. H., Kim, S. Y., \& Sheppard, K. (2009). Academic preparation in biology and advocacy for teaching evolution: biology versus non-biology teachers. Science Education, 93(6), 1122-1146. https:// doi.org/10.1002/sce.20340

Neumann, K., Boone, W. J., \& Fischer, H. E. (2014). Quantitative Research Designs and Approaches. In Handbook of Research on Science Education, Volume II. Routledge, 32-51.

O'Brien, D. T., Wilson, D. S., \& Hawley, P. H. (2009). Evolution for Everyone: a course that expands evolutionary theory beyond the biological sciences. Evolution: Education and Outreach, 2(3), 445-457. https:/ / doi.org/10.1007/s12052-009-0161-0

Osif, B. A. (1997). Evolution \& religious beliefs: a survey of Pennsylvania high school teachers. The American Biology Teacher, 552-556. https:/ / doi.org/10.2307/4450382

Reiss, M. J. (2011). How should creationism and intelligent design be dealt with in the classroom? Journal of Philosophy of Education, 45(3), 399-415. https:// doi.org/10.1111/j.1467-9752.2011.00790.x 
Rutledge, M. L., \& Mitchell, M. A. (2002). High school biology teachers' knowledge structure, acceptance \& teaching of evolution. The American Biology Teacher, 64(1), 21-28. https:/ / doi.org/10.2307/4451231

Scott, E. C. (1997). Antievolution and creationism in the United States. Annual review of anthropology, 26(1), 263-289. https://doi.org/10.1146/annurev.anthro.26.1.263

Short, S. D., \& Hawley, P. H. (2015). The effects of evolution education: examining attitudes toward and knowledge of evolution in college courses. Evolutionary Psychology, 13(1), 67-88. https:/ / doi.org/10.1177/147470491501300105

Šorgo, A., Usak, M., Kubiatko, M., Fančovičova, J., Prokop, P., Puhek, M., \& Bahar, M. (2014). A Cross-Cultural Study On Freshmen's Knowledge Of Genetics, Evolution, And The Nature Of Science. Journal of Baltic Science Education, 13(1), 6-18.

White, P. J., Heidemann, M. K., \& Smith, J. J. (2013). The effects of evolution education: examining attitudes toward and knowledge of evolution in college courses. A new integrative approach to evolution education. BioScience, 63, 586-594. https:/ / doi.org/10.1525/bio.2013.63.7.11

Wilson, D. S. (2005). Evolution for everyone: how to increase acceptance of, interest in, and knowledge about evolution. PLoS Biology, 3(12), 364. https:/ / doi.org/10.1371/journal.pbio.0030364

\section{http://www.ejmste.com}

